\title{
DESIGN AND DEVELOPMENT OF A SERIOUS GAME TO FIGHT CHILDHOOD OBESITY
}

\author{
Fátima Gonçalves ${ }^{1}$, Vítor Carvalho ${ }^{2}$, Demétrio Matos $^{3}$ \\ $12 A i$-School of Technology, Polytechnic Institute of Cávado and Ave, Barcelos, Portugal \\ 2 2Ai-School of Technology, Polytechnic Institute of Cávado and Ave, Barcelos, Portugal \\ Algoritmi Research Centre, University of Minho, Guimarães, Portugal \\ ${ }^{3}$ School of Design: ID+, Polytechnic Institute of Cávado and Ave, Barcelos, Portugal \\ a11481@alunos.ipca.pt,vcarvalho@ipca.pt,.dmatos@ipca.pt
}

\begin{abstract}
According to World Health Organization, childhood obesity, classified as the epidemic of the 21st century, is reaching alarming values all over the world. Mobile technologies, especially smartphones and tablets, are an important part of a children's life. Many studies believe that these technologies can be used in a healthy way, helping children to grow, so caregivers allow its use, on the hope that can help at their kid's development. With educational games kids learn better and faster, because they feel motivated. To contribute to the fight against this epidemic, a mobile Android application has been developed to educate and motivate children to achieve healthy lifestyles, as well as allowing caregivers to follow and be part of the process, giving them tools to contribute on the improvement on the life quality of the children.
\end{abstract}

Keywords: Obesity, Childhood, Serious Game, Mobile, Feed Day.

\section{Introduction}

Family context is the biggest influencer in children's physical and psychosocial development, mainly because it's their first learning environment.

Children's food habits are modeled by parents, family members, friends and by external factors such as various food advertisements. Increase of excessive weight and obesity at childhood, led World Health Organization - WHO [1] to declare it as the epidemic of the century.

Studies indicate that Portugal is one of the countries affected by this problem and one of the ones that will progress negatively in the future. Children's bad food habits and lack of physical activities will influence their grown up life, creating a bigger problem for the generations to come [2].

Games can be used in a casual or serious way. Playful activities are one of the most effective methodological resources to commit children in learning. This is only possible because playing is inherent to them, constituting their main way of learning [3]. What distinguishes a serious game from the others is their educational background, carefully studied and structured so that fun is not its top priority. However, this doesn't mean that they are not capable of creating entertainment and get the attention of their target audience [4]. That said, a serious game is nothing less than a learning process delivered through entertainment.
Playing is the children's job. This will allow them social interaction, as well as development of their cognitive and motor skills. Parents are children's first teachers, guiding and stimulating them since young age [5]. Playing with them while smiling, expecting children to smile back, it's just one of the simplest examples that demonstrate small challenges kids face. This will enable them the development of human interaction which will be very useful during their growth.

The American Academy of Pediatrics (AAP) argued for years that children should not have any contact with screens, be they television or mobile devices, believing that these screens could lead to a delay in the child's speech or cognitive abilities related to reading. However, the AAP and other bodies who shared the same opinion are changing your point of view, and the guidelines of zero use reformulated. It was shown to which the controlled use of screens in a fun and educational way is not necessarily harmful for children. However, now children have access to a variety of screens that provide them with information and this phenomenon leads to studies on their use are inconclusive. Thus, it becomes inappropriate to conclude that screens are harmful, or otherwise, that are always beneficial.

For this reason, the new guidelines the AAP report that children can use screens provided that the limits of responsible use are imposed [6]. 
David Hill, president of the Council on Communications and Media group, says that parents should be involved and monitor children when they are in contact with the information displayed on the screens, helping them understand the information provided, and consonance the moments in which they should have access to these devices. Thus, they will be accustomed to their presence [6]. A family game, with controlled use, allows the child and their parents can learn in a playful way, making the potential maximum advantage of this type of equipment [7].

This project intends to create a mobile app for Android devices, leading parents and their children to play together and make their relation stronger, evaluating the kid's food day through a moment of teaching and reflection from the game.

After installing the app, user must record their age and gender, among other relevant data. With this, it will be possible to change the game's behavior, to achieve the best result for the children. One example of this is the estimated calories [8].

The game is composed by a series of daily challenges and has a mascot to help on the interaction with the children. This way, they will keep motivated to play every day, allowing them to consolidate their knowledge through progressive challenges [9]. With these daily tasks, it's possible to collect their food day, and through it, change and adapt the mascot behaviors and health status. By having better food habits, they will improve the mascot health and status. This analogy between the children's food day and the mascot status leads children to be more careful and aware of the short and long-term consequences of their food habits.

This paper is organized in 4 chapters. Chapter 1 , presents the introduction. Chapter 2, presents the state of the art. Chapter 3, presents the game. Chapter 4, presents final remarks.

\section{State of the Art}

To fight the epidemic of the century new approaches are needed. The video game industry, that generates more money than Hollywood productions, are much appreciated by children. Therefore, it is considered that games can be a good tool in the prevention or treatment of childhood obesity. Games for Health $\mathrm{G} 4 \mathrm{H}$ is a new area of research and development that uses game entertainment to achieve health related goals [10].

In 2013 the number of smartphones already represented more than half of the global mobile phone market [11]. In this way, the development of new applications for these devices offers an excellent opportunity to expand the access to information regarding the health of its user, promoting the implementation of health programs, especially among children and young people, who accept easily the new technologies. With a large market, is possible to use new approaches that can have a realworld impact. Combining the tendency of young people for new technologies and the need to encourage them to change their behaviour this can be possible [12].

A serious game consists of a game that aims to educate through various ways, promoting learning as well as behavioural changes. They are a new and innovative way of educating, which is applied in many areas, such as health, helping children and adults to treat chronic diseases such as diabetes, asthma or cancer, or other psychotherapeutic treatments. The serious game on the web platform DigesTower, developed by Dias et al. [13] , intends to study and evaluate the use of such a game.

Kids in school age are DigesTower's target audience. The game uses the human digestive system in the background, and is classified as the tower defence game. When the main character, Elise, is hungry, she heads to the freezer to choose anything to eat, and the game starts. The food chosen by the user enters the digestive tract at regular intervals, and the enzymes digest each food into the correct organ. In each step, there is a brief explanation of the specific digestion functions performed by each organ. At the end of the level the user receives the feedback of the health status and is informed of his score in the game.

As conclusions of the tests made on DigesTower, it was possible to verify that is a good strategy to change the children mindset, to have a healthier diet and lifestyle, with the goal of not being overweight or even obese.

To help children and young people, that are a vulnerable segment of the population, increasing the consumption of fruits, juices and vegetables - FJV, at home and outside and believing that their consumption reduces the risk of obesity and certain types of cancer, the web game Squire's Quest I \& II were created: Implementation Intentions and Children's Fruit, Juice and Vegetable (FJV) Consumption in Baylor College of Medicine by Thompson et al. [14], in the state of Texas. Two studies were performed regarding the game, and had the following conditions: the participants must be attendants of the elementary school, need to speak and write in English, must have access to a computer and an associated tutor who also participates and supports the children in the studies. The game consisted of choosing and eating food from a pre-set menu, asking the tutors to buy it if it was not available in their homes. When a food is not to your liking, becoming an obstacle in your progression in the game, a resolution plan is defined to help the participant to eat better and rise to the next level.

The first study made to Squire's Quest I began in 2003, and aimed to register and evaluate two groups of children: in the first group the FJV consumption was analysed over 8 days; in the second group the consumption was analysed for 4 days. After the 
evaluations, they were asked to play the game, and to record the food consumption on the following 4 days. In the end, it was possible to verify that the children of the second group increased their consumption of FJV compared to those of the first group, because the children of the first group were object of a more intensive testing and got bored, leading to a general disinterest on the game.

The second study, carried out in version II, was performed between 2009 and 2011, and its main purpose was to test the effects of creating FJV consumption goals attributed to participants while they were playing Squire's Quest. In this study, participating children were to play all 10 levels, while tutors were given a newsletter for each of those levels, as well as web access where they could collect information on healthy foods and participate in data collection activities. A small subset was randomly selected to participate in an interview about the study and its effect on the home food environment. As conclusion of this study, there was an increase in FJV consumption in each participant.

Nutri Ventures is an educational project with the support of several nutritionist associations that guarantee and validate the developed content.

Their main goal is to change the eating habits of children worldwide, seeking through entertainment, tools that make children's nutrition healthier and fun. For this, they have games in which food is a central part of the story, leading children to create good relationships with all foods. To spread the message, the company created a child television show with musical contents, as well as a digital platform where children can play adventures of nutrition [15].

On the child growth phase, it's extremely important that she has a healthy eating and therefore is essential to choose safe foods regarding quality and hygiene and they need to meet all the necessary and essential nutrients.

The energy requirements in this group age are entirely dependent on the needs required for the organism normal needs, for the growth and by the energy expenditure that is inherent for the physical activity. On average, the needs range from 1.300 calories for children with three years old and 1.700 for children with the age of six. It is also worth to note that, in average, female children need less 150 calories when compared to male children, because they have lower energy needs [16].

The distribution of the total daily caloric value should focus on the following percentages of macronutrients, $60 \%$ carbohydrates, $27 \%$ fat and $13 \%$ protein, divided as follows during the day: breakfast $15 \%$, morning snack $5 \%$, lunch $35 \%$, afternoon snack 15\% and dinner 30\% [16].

From the research carried out, it was not possible to find a mobile application that covered the gaming side as well as the analysis of the evolution of the user that the caregivers could follow, so that they could avoid or combat the child's health problems. The mobile application was created on Android, named Barty, and will help children and caregivers to educate and fight childhood overweight and obesity.

\section{The Game}

To fight the epidemic of the century new approaches. Symbols were created and transformed along several generations to be part of their religion or visual art. They become a tool for understanding the world. Erich Fromm classifies the symbols into two categories: conventional or accidental and universal. The conventional ones are used for informational purposes, while the universal ones have a wide and deeper meaning. Before the discovery of the main function of the heart, it was seen as the center of life, courage and reason, being the most universal of the existing symbols [17].

The figure of the heart has evolved and the rounded representation in the shape of a peach appears for the first time, with a groove in the upper part, in an anatomy work of Vigevano in 1347. At present days, the symbol of the heart isolated or crossed by an arrow of Cupid is the universal symbol of love [17].

With the believing that a symbol that represents love and life, would be the best way for the interaction with parents and children, Barty was created, Fig.1.

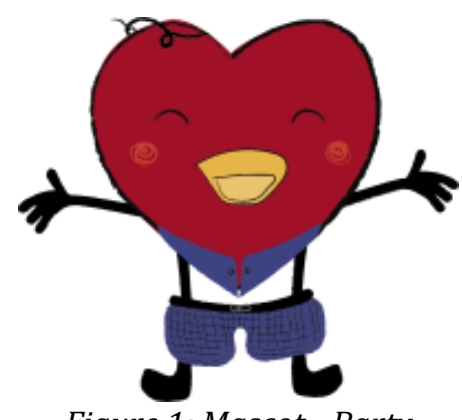

Figure 1: Mascot - Barty

This central character of the game takes the form of a heart and interacts with parents and children so that they live life with love and a healthy body. The name Barty has originated in the union of the words Body and Hearty.

The representation of this symbol was not intended to have a high level of abstraction so that the meaning was not explicit, but also not to include a great level of detail that could lead to an unpleasant symbol and could also lose the meaning of love.

In this context, we followed a compromise between abstraction and reality, following the ideals of illustrator and graphic designer Christoph Niemann who developed The Abstract-o-Meter [18] represented in Fig.2. 


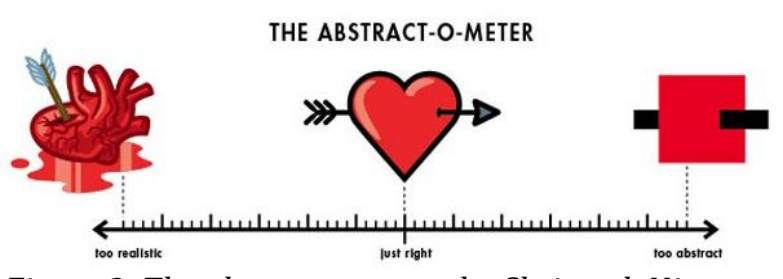

Figure 2: The abstract-o-meter by Christoph Niemann [18] Fig.3:

The application consists of five main sections,

\section{List of configured users; \\ 2. Control of information \\ accessible by caregivers; \\ 3. Presentation of the \\ character varying according \\ to the level and state defined \\ in the user; \\ 4. Challenge(s) presented to \\ users; \\ 5. Addition of a new user.}

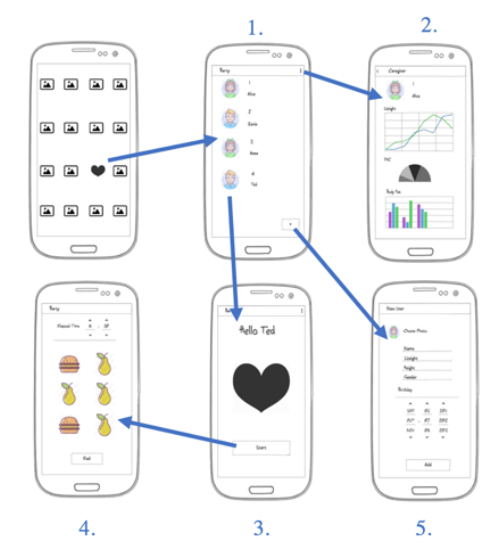

Figure 3: Game mockup

The user information and caregiver responsible for the users of each application is stored in the android internal database through SQL Lite, following the structure defined in Fig.4.

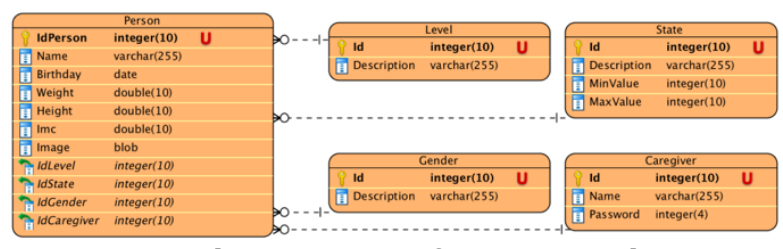

Figure 4: Database structure for person and caregiver

For each user who wants to register, they are asked to enter their name and photo so that it is easily identified in the users list. The date of birth and gender are required so that the calorie values on the child's feed day can be adapted to their age group and gender. Weight and height registration are important for evaluating user evolution.

The caregiver association in each installation of the application is important because only with this it will be possible to draw conclusions about the evolution of all responsible users and caregivers. The password allows only the caregiver to have access to sensitive (personal) information about all users, and the ability to edit or remove users. In the information only accessible by the caregiver it's still possible to make an analysis of the child's evolution in a given game, for example, how many movements he needs to overcome a given challenge or even the time needed to finish it, being able to evaluate his performance over time.
Figure 5 presents what could be the interface for the caregiver to manage the evolution of each child.

The registration of new users is available without any type of control, because it is not intended to limit access to the application.

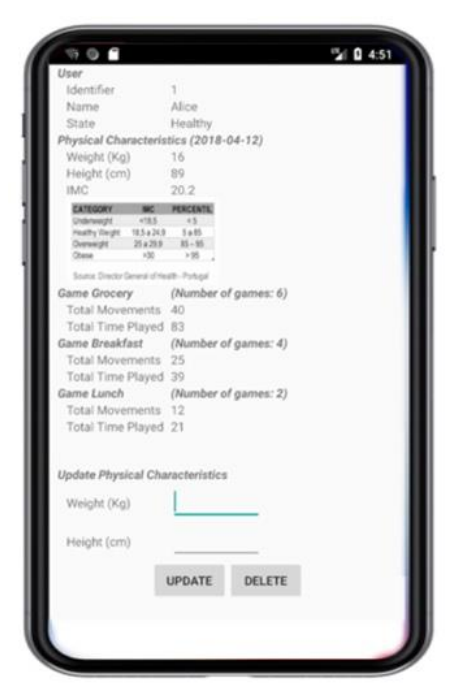

Figure 5: Caregiver interface mockup

The levels will have the following definition: beginner, intermediate and advanced, which will influence the way Barty is dressed.

On the other hand, each level is associated to four states, every quarter of $100 \%$, which influence the physical and colour aspect of Barty:

Table 1. Influence the physical and colour aspect

\begin{tabular}{|l|l|}
\hline $\begin{array}{l}\mathbf{0 - 2 5 \%} \text { - green colour, } \\
\text { fat and sad }\end{array}$ & $\begin{array}{l}\mathbf{2 5 - 5 0 \%} \text { - yellow } \\
\text { colour, slimmer and } \\
\text { listless }\end{array}$ \\
\hline $\begin{array}{l}\mathbf{5 0 - 7 5 \%} \text { - orange } \\
\text { colour, athletic shape } \\
\text { and joyful }\end{array}$ & $\begin{array}{l}\mathbf{7 5 - 1 0 0 \%} \text { - red } \\
\text { colour, athletic shape } \\
\text { and very cheerful }\end{array}$ \\
\hline
\end{tabular}

The main page of the game Barty appears with the corresponding aspect with the level and state of the user selected. In this screen, it's possible that the user initiates new challenges that, when finalized, can affect the level and state of the mascot.

To motivated the child to use the application, the educational side cannot be very explicit, the games should be catchy and Barty must interact with the user, stimulating him to play new challenges with increasing complexity. Taking care about the age range for which the game is intended, audio should be used to voice the mascot, as well as for successful or failed game actions, or other touching options.

The database structure that will store the information regarding the proposed challenges has not yet been defined, but should contain the designation of the layout of each game available in the application, the level of difficulty and other information that can be considered relevant during implementation. 


\section{Conclusions}

Due to the relevance of preventing childhood obesity, a serious game is being developed with the purpose to give the child, a better understanding on food habits, by guiding them on good food habits. This game will be tested in children between 3 and 6 years old.

As future work, it is necessary to define the best challenges for the children, implement information management accessible by caregivers and include audio to help younger children, as well as performing real world tests to validate the game objective.

The state of the mascot should reflect the evolution in the child's recent responses, motivating it with its alteration of appearance, also putting the explanation of the change in a more explicit way.

\section{Acknowledgements}

The authors would like to express their acknowledgements to the nutritionists Ana Miranda and Mariana Afonso for the follow-up on the development stage of this application, which led to the use of the best practices of nutrition, and to COMPETE: POCI-01-0145-FEDER-007043 and FCT Fundação para a Ciência e Tecnologia within the Project Scope: UID/CEC/00319/2013.

\section{References}

[1] World Health Organization, "Report of the commission on ending childhood obesity," World Health Organization, Geneva, 2016.

[2] E. M. do V. Leiras and E. M. do Vale, "Comportamento alimentar da criança: a influência materna," 2015.

[3] C. F. P Ramos, F. Pascoal Ramos, L. Amparo da Silva Santos, and A. Borba Costa Reis, "Educação alimentar e nutricional em escolares: uma revisão de literatura," vol. 29, no. 11, pp. 2147-2161, 2013.

[4] D. Djaouti, J. Alvarez, J.-P. Jessel, and 0. Rampnoux, “Origins of Serious Games," 2011.

[5] J. K. Anderson-McNAmee and S. J. Bailey, "The Importance of Play in Early Childhood Development," Mont. State Univ. Ext. MontGuide, 2010.

[6] A Heid, M. (2016). Inside the New Standards for Kids and Screen Time.: Sistema de descoberta para FCCN. Retrieved from http://eds.b.ebscohost.com/eds/pdfviewer/pdfvi ewer?vid=1\&sid=3fbf542f-f3f1- $454 \mathrm{e}-8522$ -

8096528c3bd9\%40sessionmgr102

[7] McEwen, R. N., \& Dubé, A. K. (2015). Engaging or Distracting: Children's Tablet Computer Use in Education.: Sistema de descoberta para FCCN. Retrieved from http://eds.b.ebscohost.com/eds/pdfviewer/pdfvi ewer?vid=1\&sid=09414855-73d7-4cb2-b6b213bd724fe695\%40sessionmgr101

[8] Gonçalves, F., Carvalho, V., \& Matos, D. (2019). "Barty" - A Serious Game to Fight Childhood Obesity: First Insights. In J. Machado, F. Soares, \& G. Veiga (Eds.), Innovation, Engineering and Entrepreneurship. HELIX2018 (pp. 259-266). Cham: Springer International Publishing.

[9] L.-C. Wang and M.-P. Chen, "Innovations in Education and Teaching International," 2017.

[10] T. Baranowski, "Might Video Games Help Remedy Childhood Obesity?". Child. Obes., vol. 11, no. 4, pp. 331-334, Aug. 2015.

[11] J. P. Pereira, "Smartphones em Portugal ultrapassaram telemóveis tradicionais PÚBLICO," 2014. [Online]. Available: https://www.publico.pt/2014/02/20/tecnologia /noticia/smartphones-em-portugalultrapassaram-telemoveis-tradicionais-1624400. [Accessed: 30-Dec-2016].

[12] D. Fitton and B. Bell, "Working with Teenagers within HCI Research: Understanding TeenComputer Interaction," 2014, pp. 201-206.

[13] J. D. Dias et al., "Serious game development as a strategy for health promotion and tackling childhood obesity," Rev. Lat. Am. Enfermagem, vol. 24, 2016.

[14] D. Thompson et al., "Creating action plans in a serious video game increases and maintains child fruit-vegetable intake: a randomized controlled trial.," Int. J. Behav. Nutr. Phys. Act., vol. 12, p. 39, Mar. 2015.

[15] "Nutriventures." [Online]. Available: http://www.nutri-ventures.com/pais/pt. [Accessed: 26-Aug-2017].

[16] E. Nunes and J. Breda, Manual para uma alimentação saudável em jardins de infância. Lisboa.

[17] P. R. Prates, "The heart as symbol". História, Ciências, Saúde - Manguinhos, vol. 12, pp. 102531, 2005.

[18] "Abstract-0-Meter | Christopher Simmons." [Online]. Available: http://minesf.com/resources/cca/2010/01/25/ abstract-o-meter/. [Accessed: 30-Sep-2017]. 